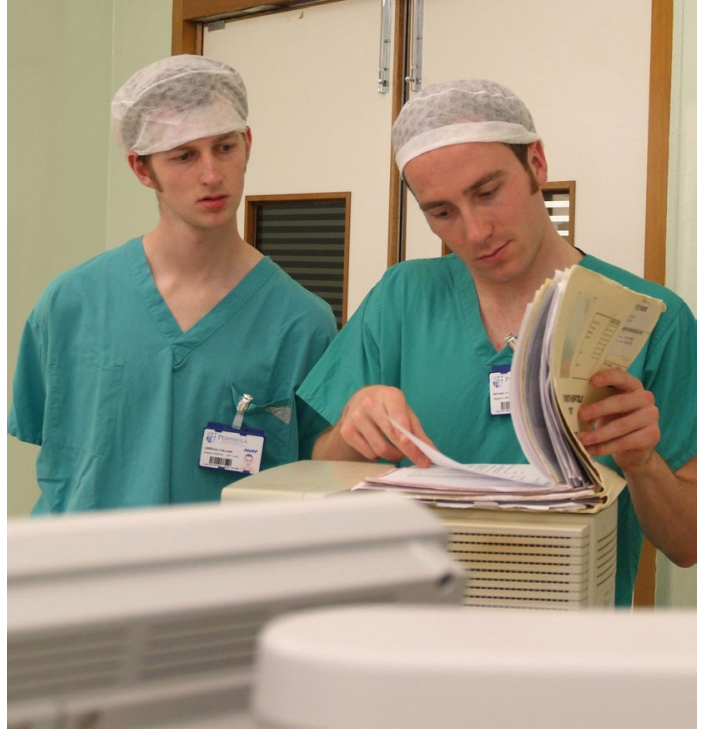

\title{
High value
}

care

\section{Are medical students trained in cross-cover?}

\section{Lauren A Heidemann ${ }^{1}$ (D) , James T Fitzgerald ${ }^{2,3}$ and Sarah Hartley ${ }^{1}$}

${ }^{1}$ Department of Internal Medicine, University of Michigan, Ann Arbor, Michigan, USA 2Department of Learning Health Sciences, University of Michigan, Ann Arbor, Michigan, USA

${ }^{3}$ Geriatric Research Education and Clinical Center, Arbor VA Medical Center, Ann Arbor, Michigan, USA

We identified

gaps in cross-

cover training

and in the

preparedness

of incoming

interns

\section{SUMMARY}

Objectives: To examine the current state of cross-cover education in undergraduate medical education and intern perceived readiness to provide cross-cover.

Methods: An electronic survey was distributed to 126 incoming interns in surgery, internal medicine, family medicine and paediatrics residencies at a single academic centre.

Information regarding prior cross-cover training, experience, confidence, and responses to a sample cross-cover case were obtained.

Results: The survey response rate was $69.8 \%$ (88 of 126), which included both partial and complete responses. Fifty-seven interns out of $85(67.1 \%)$ had no formal training and 51 (60.0\%) had no experience performing cross-cover. They reported feeling unprepared to provide crosscover, with an average score of 1.8 on a 5 -point Likert scale (1, not at all confident; 5 , extremely confident). Interns had more confidence in performing crosscover tasks if they had prior direct cross-cover experience $(p=0.001)$, and were the least confident in performing the initial evaluation and management of urgent issues (Likert score $=1.6$ ). Scores on the sample case were correlated with the amount of prior experience with patients $(p=0.06)$. Only $77.7 \%$ of interns indicated that they would notify their senior resident in two urgent scenarios. Those who reported higher confidence in knowing when to ask for help were more likely to appropriately notify their senior colleague $(p=0.005)$.

Conclusions: We identified gaps in cross-cover training and in the preparedness of incoming interns. This has important implications for the first day of residency, when interns are often asked to perform cross-coverage, yet feel unprepared to do so and express the greatest concern in urgent cross-cover scenarios. Addressing this curricular gap is crucial in assuring safe crosscover care. 
ross-cover is the practice of caring for hospitalised patients when the primary team is absent from the hospital. ${ }^{1}$ The initiation of Accreditation Council for Graduate Medical Education (ACGME) restricted duty hours has led to increased patient handovers and a discontinuity of care for hospitalised patients. ${ }^{2,3}$ As a result, the time that physicians spend in providing cross-cover has increased significantly. A common example of cross-cover is when interns working overnight (night shift) care for patients admitted by the day teams of their respective specialties (e.g. a general surgery night intern caring for general surgery daytime patients).

Providing cross-cover encompasses several unique challenges. ${ }^{1}$ First, interns are not intimately familiar with the patient's circumstances and often have not participated in the development of the care plan. Second, interns must determine the urgency of addressing the concern (i.e. when they can defer an issue to the primary team versus the need to see a patient immediately), and when to notify their senior (supervising) resident. Finally, the cross-cover mindset is such that 'quick fixes' may be considered acceptable, given the feeling of a lack of responsibility for the patient. $^{1}$

Extensive literature exists describing end-of-shift handovers $^{* 4,5}$ however, the training that medical students receive about cross-cover care (i.e. how they use the handover) is unknown. Our purpose was to describe the current state of cross-cover education of interns who are starting residency at a single academic institution from a broad range of medical schools. The research questions were:
- Do students receive crosscover training, and if so, what types of training?

- Does previous cross-cover experience during medical school affect intern confidence levels?

- Does cross-cover training or experience during medical school result in greater knowledge?

\section{METHODS}

\section{Setting}

An anonymous survey was distributed electronically using QUALTRICS (Qualtrics LLC, Provo, UT, USA) to incoming interns in internal medicine $(n=44)$, internal medicine preliminary year (e.g. neurology residents spending their first year in internal medicine, $n=8)$, medicine-paediatrics $(n=8)$, paediatrics $(n=24)$, family medicine $(n=11)$, general surgery $(n=7)$ and general surgery preliminary year (e.g. urology, orthopaedic surgery residents spending their first year in general surgery, $n=24$ ) at a single academic tertiary care centre in 2017 during intern orientation, prior to patient care responsibilities.

\section{Survey instrument}

Demographic data were collected including gender, medical school, and residency specialty. The survey inquired about cross-coverage training and experience, and perceived readiness to perform cross-coverage (Table 1 ).

Interns were also presented with a case of an 18-year-old patient hospitalised with a severe ulcerative colitis flare. They were asked to respond to seven cross-cover scenarios and to choose from the following actions: (i) no action; (ii) enter order for diagnostic test or therapy; (iii) evaluate and/or discuss with patient at bedside, and (iv) defer to primary team. The interns were also asked if they would notify their senior resident for each scenario. The survey was reviewed prior to distribution by programme leadership in surgery, paediatrics, internal medicine, family medicine and medicine-paediatrics. Using this input, the physician investigators (LAH, $\mathrm{SH}$ ) assigned points to each response ranging from +2 points for the most appropriate response to -2 points for potential harm. The survey is published online as supporting information (Appendix S1).

\section{Definitions}

The fourth year of medical school (M4) was defined as the final year of medical school. Subinternship was defined as an M4 rotation in which students take on the responsibilities of an intern in a supervised setting. 'Formal training' was defined as lecture-based or simulated paging scenarios, and 'informal training' was defined as observing others provide cross-coverage or discussion with a faculty member or senior resident. 'Low experience' was defined as providing cross-coverage for 15 or fewer patients, and 'high experience' was defined as providing cross-coverage for 16 or more patients. Regarding the case, 'urgent' scenarios were defined as those that could cause potential patient harm if not addressed promptly; all others were considered 'routine'.

\section{Statistical analyses}

Participant demographic information and nominal data are reported as frequencies; Likert scales and test scores are reported as means and standard deviations. Analyses of variance (ANOVAS) were used to analyse the mean differences in interns' confidence levels by prior training received and by level of experience. ANova was also used to analyse test scores and sub-scores by prior training received and by level of experience. Post hoc differences were determined by the Tukey-Kramer honestly significant difference (HSD) test (global $p=0.05)$. All
Cross-cover is the practice of caring for hospitalised patients when the primary team is absent from the hospital 
Providing

cross-cover

encompasses

several unique

challenges
Table 1. Cross-cover survey instrument distributed to incoming interns, July 2017

Question domain Sample item

Response options/scoring

Medical school
training

During medical school, did you receive training and/or education

Yes/No

in the care of cross-cover patients?

What type(s) of training and/or education did you receive during Yes/No medical school concerning cross-cover patients?

- I attended a formal lecture on cross-cover evaluation and/or management.

- I had informal teaching (i.e. faculty member discussed it with me)

- I observed others providing cross-coverage

- I participated in standardised patient assessments or mock paging exercises

- I have not had any training/education

Patient experience When were you personally responsible for providing cross-coverage on hospitalised patients?

a. M3 clerkship

b. M4 sub-internship

c. M4 elective

d. Night float rotation

e. I was not personally responsible

How many patients have you directly provided cross-coverage for during your medical school training?

a. None

b. 1-15 patients

c. $16-30$ patients

d. More than 30 patients

Confidence level How would you rate your level of confidence for the following entering intern- inpatient cross-cover activities? ship

- Triaging cross-cover issues

- Performing the initial evaluation and management of routine cross-cover issues

$1=$ Not at all confident 2 = Somewhat confident 3 = Moderately confident $4=$ Very confident

$5=$ Extremely confident

- Performing the initial evaluation and management of urgent or emergent cross-cover issues

- Communicating with nurses about cross-cover patients

- Knowing when to ask for help with cross-cover patients

Self-reported preparedness

How prepared do you feel to take cross-cover as you start your intern year?

$1=$ Not at all prepared $2=$ Somewhat prepared 3 = Moderately prepared $4=$ Very prepared $5=$ Extremely prepared

Additional medical Would more education and/or practice opportunities with crossschool training cover during medical school have helped you feel more prepared?

Abbreviations: M3, third-year medical student; M4, fourth-year medical student.

analyses were completed using JMP PRO 13.1 (SAS Institute, Inc.., Cary, NC, USA).

The study was determined to be exempt from review by the University of Michigan
Institutional Review Board (HUM00131005).

\section{RESULTS}

The response rate was $69.8 \%$ (88 out of 126): 78 completed the entire survey and 10 provided partial responses. Response rates varied by department (Table 2). The interns represented 39 medical schools across the USA. 
Table 2. Demographic data for 88 incoming intern survey respondents, 2017
Residency programme $(n=88)$ $\%(n)$
Family medicine
General surgery
Categorical
Preliminary
Internal medicine
Categorical
Preliminary
Medicine-paediatrics
Paediatrics
Gender $(n=87)$
Female
$50.6(44)$
Male
$49.4(43)$

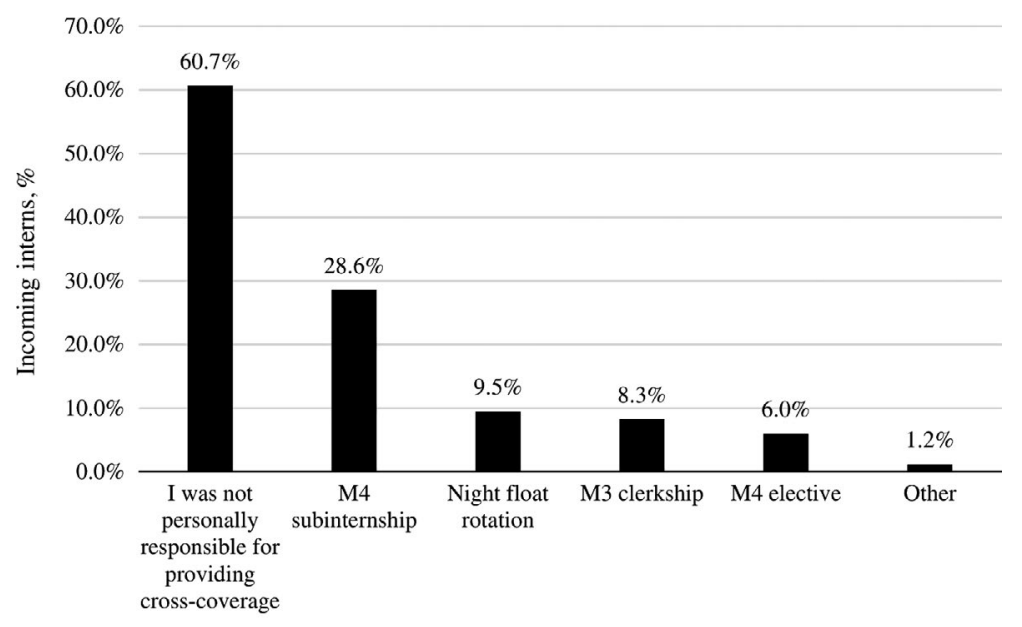

Rotation with cross-cover experience

Figure 1. Medical school experience of 84 incoming interns providing cross-cover by rotation type in 2017. M3 = third-year medical student; $M 4$ = fourth-year medical student; 0ther = preliminary year. The percentages do not add up to $100 \%$ as interns $(n=84)$ could choose more than one item.

\section{Prior cross-cover training}

Eighty-five respondents answered the question on prior cross-cover training. Of these, $37(43.5 \%)$ reported no prior formal or informal training in cross-coverage. Of the 47 interns (55.3\%) who had received training, $36(76.6 \%)$ had received informal teaching by a resident or faculty member, 36 (76.6\%) had observed others providing crosscover, $18(38.3 \%)$ had received a lecture(s), and 18 (38.3\%) had participated in simulated paging exercises. preparedness was $1.8 \pm 0.7$.

Interns felt least prepared in performing the initial evaluation and management of emergent situations $(1.6 \pm 0.7)$. Confidence in global cross-cover preparedness was greater in interns with high experience in medical school compared with those with no experience $(p=0.001)$ (Table 3$)$.

\section{Sample cross-cover case}

The mean \pm SD percentage score on the practice cross-coverage case was $75.8 \pm 10.3 \%$. Although total scores tended to improve with greater experience, there were no significant differences among interns with no prior experience, low experience, and high experience $(74.0 \%$ versus $76.8 \%$ versus $82.4 \%$; $\mathrm{p}=0.06)$.

Interns notified the senior resident $77.7 \%$ of the time for urgent cross-cover issues. There was no difference based on previous training regarding appropriate notification of their senior resident; however, interns with increased confidence in knowing when to ask for help were more likely to notify their senior appropriately $(p=0.01)$ (Figure 2).

\section{DISCUSSION}

This study highlights several gaps in the perceived and expected training of incoming interns with regard to crosscover care. First, experience in providing cross-coverage varies broadly, with most interns reporting no experience or formal training. Second, incoming interns report low confidence in many areas of cross-coverage regardless of previous training, with the lowest self-reported confidence in the ability to perform the initial evaluation and management of urgent scenarios. Third, interns vary in their threshold of when to notify a senior resident about cross-cover issues.
This study highlights several gaps in the perceived and expected training of incoming interns with regard to crosscover care

\section{Intern confidence}

Using the 5-point Likert scale (1, not at all prepared; 5 , extremely prepared), the mean \pm SD score reported for overall 
The majority of

interns

surveyed feel

unprepared to

provide cross-

cover, especially

in urgent

scenarios

Table 3. Self-reported confidence of 85 incoming interns performing cross-cover by previous experience, 2017

\begin{tabular}{|c|c|c|c|c|c|}
\hline Cross-cover task & $\begin{array}{l}\text { No experience } \\
\text { (Mean } \pm \text { SD) }\end{array}$ & $\begin{array}{l}\text { Low experience } \\
\text { (Mean } \pm \text { SD) }\end{array}$ & $\begin{array}{l}\text { High experience } \\
(\text { Mean } \pm \text { SD) }\end{array}$ & $p$-value ${ }^{a}$ & $\begin{array}{l}\text { Post hoc } \\
\text { test }^{b}\end{array}$ \\
\hline $\begin{array}{l}\text { Preparation to take cross-cover } \\
\text { (global) }\end{array}$ & $1.6 \pm 0.7$ & $2.0 \pm 0.6$ & $2.3 \pm 0.8$ & 0.001 & High $>$ No \\
\hline Triage & $1.7 \pm 0.7$ & $2.1 \pm 0.4$ & $2.4 \pm 0.7$ & $<0.001$ & High>No \\
\hline $\begin{array}{l}\text { Initial evaluation and management } \\
\text { of urgent or emergent issues }\end{array}$ & $1.6 \pm 0.7$ & $1.6 \pm 0.7$ & $1.8 \pm 1.0$ & 0.82 & - \\
\hline $\begin{array}{l}\text { Initial evaluation and management } \\
\text { of routine issues }\end{array}$ & $1.9 \pm 0.8$ & $2.3 \pm 0.6$ & $2.7 \pm 0.7$ & 0.001 & High $>\mathrm{No}_{0}$ \\
\hline Communication with nurses & $2.0 \pm 0.1$ & $2.4 \pm 0.2$ & $3.0 \pm 0.2$ & 0.002 & High>No \\
\hline Knowing when to ask for help & $2.1 \pm 0.1$ & $2.4 \pm 0.2$ & $3.0 \pm 0.3$ & 0.01 & High $>$ No \\
\hline
\end{tabular}

Confidence level assessed using a 5-point Likert scale: 1, not at all confident; 5, extremely confident.

Experience levels: no experience, no prior direct cross-cover care; low experience, prior experience cross-covering for 1-15 patients; high experience, prior experience cross-covering for $\geq 16$ patients.

ane-way ANova test with post hoc comparisons using the Tukey-Kramer honestly significant difference (HSD) test (global $p=0.05)$.

${ }^{\mathrm{b}}$ Tukey-Kramer HSD post hoc comparisons (global $\left.p=0.05\right)$.

D
0
0
0
0
0
0
$\pi$
0
0
0
0
0
0
0
0
0
0
0
0
0
0
0
0
0
0
0
0
0
0
0
0
0
0
0
0

$90.0 \%$

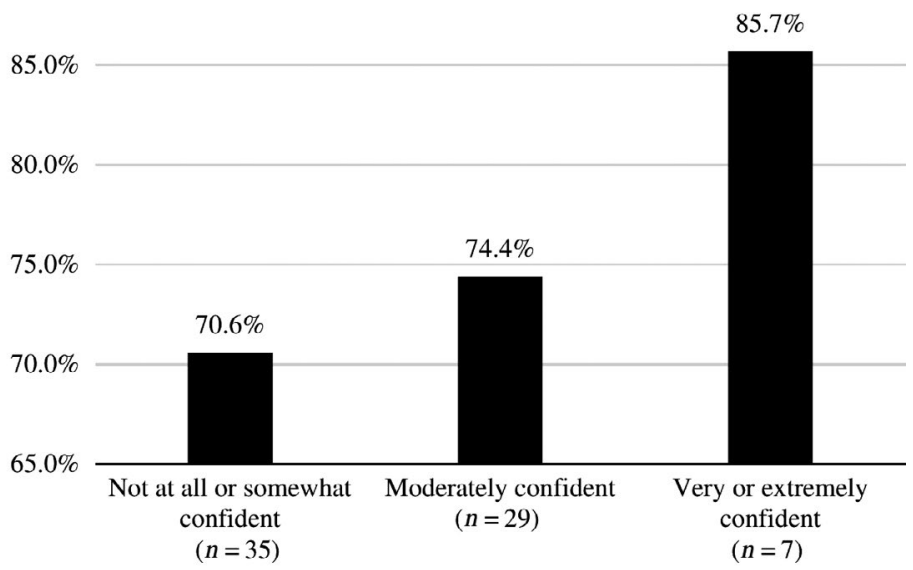

Self-reported confidence regarding when to ask for help

Figure 2. Seventy-one incoming interns' self-reported confidence score and appropriate notification of senior resident about cross-cover issues (\% score) in 2017. One-way Anova test comparing low confidence ('not at all' or 'somewhat confident'), moderate confidence, and high confidence ('very confident' or 'extremely confident'), $\mathrm{p}=0.01$.

The majority of interns surveyed feel unprepared to provide crosscover, especially in urgent scenarios. Possible explanations include that medical students are not given the opportunity to manage urgent scenarios, they are protected from providing cross-coverage for seriously ill patients and that the acuity of the situation leads to greater anxiety and therefore less confidence. This represents a gap in the perceived and expected requirements of graduated medical students, given that initial evaluation of urgent scenarios is defined as an entrustable professional activity by the Association of American Medical Colleges. ${ }^{6}$

The sample cross-cover case revealed that almost a quarter of interns would not notify their senior residents about urgent clinical scenarios. Interns are often the frontline physicians; if they do not identify that a patient has an urgent problem, this may lead to adverse outcomes. ${ }^{7}$ Prior survey data from both internal medicine programme directors and residents indicate that knowing when to seek assistance is one of the most important skills for new interns. ${ }^{8,9}$ Our data demonstrate that interns with increased confidence in asking for help are more likely to do so appropriately. Hence, it may be worthwhile assessing incoming interns' self-perceptions of their ability in this task to identify those who may need additional intervention in this area.

This study has several limitations. It was performed at a single academic institution. The survey was distributed during intern orientation, a time that can be anxiety-provoking. Lastly, the sample case was not validated based on training level. The strengths of this study 
include representation from a broad range of medical schools and residency programmes, and a high survey response rate.

In conclusion, the diversity in cross-cover training, low confidence of trainees and difficulty in knowing when to ask for help when transitioning into the intern role highlight gaps in preparation for the first day of internship. Based on these data, we suggest that formal cross-cover curricula be implemented in medical schools and intern orientation, with a focus on urgent scenarios as well as guidance on when to ask for help. This could be performed through the incorporation of supervised cross-cover into subinternships, or simulated paging curricula in which cross-cover decision-making skills can be formally assessed. ${ }^{10}$ Until this is implemented, there is a need for increased awareness in graduate medical education about the diversity of cross-cover preparedness of incoming trainees, and a need to assess whether a trainee will seek assistance when needed.

\section{REFERENCES}

1. Kakarala K, Jain SH. The "crosscover" mindset. J Patient Saf 2012;8(1):1-2.

2. Desai SV, Feldman L, Brown L et al. Effect of the 2011 vs 2003 duty hour regulation-compliant models on sleep duration, trainee education, and continuity of patient care among internal medicine house staff: a randomized trial. JAMA Intern Med 2013;173(8):649-655.

3. Drolet BC, Khokhar MT, Fischer SA. The 2011 duty-hour requirements - a survey of residency program directors. $N$ Engl J Med 2013;368(8):694-697.

4. Vidyarthi AR, Arora V, Schnipper JL, Wall SD, Wachter RM. Managing discontinuity in academic medical centers: strategies for a safe and effective resident sign-out. J Hosp Med 2006;1(4):257-266.

5. Starmer AJ, Spector ND, Srivastava $R$ et al. Changes in medical errors after implementation of a handoff program. N Engl J Med 2014;371(19):1803-1812.

6. Flynn T, Cali S, Carraccio C et al. Core Entrustable Professional Activities for Entering Residency. Curriculum Developers' Guide. Washington, DC: AAMC; 2014.

7. Wilson RM, Harrison BT, Gibberd RW, Hamilton JD. An analysis of the causes of adverse events from the Quality in Australian Health Care Study. Med J Aust 1999;170(9):411-415.

8. McQuillan $P$, Pilkington $S$, Allan A, Taylor B, Short A, Morgan G, Nielsen M, Barrett D, Smith G, Collins $\mathrm{CH}$. Confidential inquiry into quality of care before admission to intensive care. BMJ 1998;316(7148):1853-1858.

9. Angus SV, Vu TR, Willett LL, Call S, Halvorsen AJ, Chaudhry S. Internal medicine residency program directors' views of the core entrustable professional activities for entering residency: an opportunity to enhance communication of competency along the continuum. Acad Med 2017;92(6):785-791.

10. Frischknecht $A C$, Boehler ML, Schwind $\mathrm{CJ}$, Brunsvold ME, Gruppen LD, Brenner MJ, Hauge LS. How prepared are your interns to take calls? Results of a multiinstitutional study of simulated pages to prepare medical students for surgery internship. Am J Surg 2014;208(2):307-315.

\section{SUPPORTING INFORMATION}

Additional supporting information may be found online in the Supporting Information section at the end of the article

Appendix S1. Cross-cover survey for incoming interns.

Corresponding author's contact details: Lauren A Heidemann, Department of Internal Medicine, 3119 Taubman Center, 1500 E Medical Center Drive, SPC 5376, Ann Arbor, Michigan 48109-5376, USA. E-mail: theidema@med.umich.edu

Funding: None.

Conflict of interest: None.

Acknowledgements: None.

Ethical approval: The study was determined to be exempt from review by the University of Michigan Institutional Review Board (HUM00131005).

doi: $10.1111 /$ tct.12803 